\title{
The strategist's bookshelf
}

\section{How should I know?}

\author{
Harvey A. Hornstein
}

All You Have to Do Is Ask by Wayne

Baker (Currency, 2020).

Google Maps saved me. Before its availability I was one of those automobile drivers who refused to ask for directions. When I was lost, driving here and there searching for my destination, the barely veiled criticism regularly hurled at me by family members was, "All you have to do is ask." This is the very appropriate title of the seven chapter, 165-page book by Wayne Baker (224 total pages including notes, appendix and index) which thoroughly addresses the problem of inveterate non-askers. It's an especially timely book because, as corporations struggle and go far afield in their search to produce continuous innovation, employees must leave the main path and seek information and allies amid unfamiliar technologies and markets.

Organizations' employees need to be able to ask for help and confident they will get it. For example, would-be innovators need an ecosystem of advisors. Even top leaders need to ask what customers are saying to front-line employees. And every employee likely has questions about how the ever-changing digital systems affect their jobs. And, as this book's author claims in his opening chapter, "Just Ask and Miracles Happen," whether employees have the ability to ask can affect their own and their organizations' success or failure. Specifically, according to the author, asking for help has eight potential organizational benefits. Summarized, they are:
1. Increasing job performance and satisfaction because of the information, assistance and cooperation that others may provide.

2. Providing new occupants of positions with a helpful orientation to the critical features of their new jobs.

3. Meshing people's job-relevant talents with jobs' skill requirements by increasing the pool of relevant information.

4. Raising the ability to identify and possibly pursue areas identified as needing improvement as a consequence of greater flows of diagnostic information about employees' job-related skills.

5. Sparking innovation and creativity by the surge of information that the asking and answering produce.

6. Reducing the questioner's stress because of either, or both, the answers' content and the support signified by respondents' efforts to answer.

7. Improving team performance because the answers' information improves either, or both, individual ability and interpersonal coordination.

8. Declining costs as employees' speed to reaching solutions increases.

Like the opening chapter in Part One ("The Power of the Ask") of this twopart book, the two remaining
Harvey A. Hornstein, Professor of Psychology, Emeritus, formerly with the Program in Social and Organizational Psychology at Teachers College, Columbia University, now operates a private organizational consulting practice (harvey.hornstein@gmail.com). He has written nine books, including Brutal Bosses and Their Prey (1997). 


\section{"Skillfully asking for help and answering calls for help are indispensable to organizational success."}

chapters, "A Human Dilemma: It's

Hard to Ask for Help" and "The Law of

Giving and Receiving" are filled with

examples from well-known

organizations. These illustrate the

many different ways in which skillfully

asking for help and answering calls

for help are indispensable to

organizational success.

Part two of the book ("Asking for (and getting) what you need: A toolkit')

fulfills its title's promise by providing readers with activities that they can use to hone their skills in asking for, receiving and giving help. In addition, its four chapters contain specific information guiding readers to tools being used by organizations to enhance these skills in their employees:

- "Get started now: Figuring out what you need and asking for it."

- "Tools for teams."

- "Asking across boundaries."

- "Recognition and rewards."

By providing these skill-focused activities and this information, the book becomes more than a review of the benefits accruing to organizations that support members' skillful requests for help. It is a tool that leaders can use to improve their competence in asking for and giving help as well as in constructing climates in their own organizations that support these exchanges.

Additional applause goes to the author, Professor of Business Administration and organizational management at University of Michigan Ross School of Business, for ending all but the first of this book's chapters with "summary" and "reflections and actions" sections. As its title promises, the former briefly reminds readers of the chapter's principle arguments and ideas. The latter section, however, does more. By inviting readers to apply the chapter's arguments and ideas to their lives inside and outside the workplace, it has the potential of becoming a self-help tool for readers. For example, the first item in the "reflections and actions" section following Chapter 2, "A Human Dilemma: It's hard to ask for help" is, "Of the eight reasons why it's hard to ask for help, which ones stand out as the biggest obstacles for you? Why?" In this instance, the author provides readers with an opportunity to examine and possibly alter their behavior in the "asking arena." As this illustration suggests, readers who can work with the questions in these "reflections and actions" sections may find them to be useful pathways to important self-insight and skill development.

The book's last three chapters are concerned with making organizations safe places for asking questions. Readers are provided with techniques designed to make it safer for employees to ask for and give help within their teams and across group boundaries. The author successfully stimulates readers' thinking about the value of asking questions in organizations as well as the circumstances that support or inhibit such inquiries, a largely neglected issue. Even more, he provides readers with tools, as well as roadmaps for locating tools, that should help them and their organizations successfully reach desired destinations. It seems a simple concept, but the power of asking may be the next best thing for getting us where we want to go since Google Maps.

\section{Corresponding author}

Harvey A. Hornstein can be contacted at: harvey.hornstein@ gmail.com 